\title{
Micro-computerized tomography analysis of cement voids and pull-out strength of glass fiber posts luted with self-adhesive and glass-ionomer cements in the root canal
}

Sarıdağ, Serkan ; Helvacıŏ̆lu-Yiğit, Dilek ; Özcan, Mutlu ; Avcu, Egemen ; Kızıltaş, Güllü

DOI: https://doi.org/10.1080/01694243.2016.1155911

Posted at the Zurich Open Repository and Archive, University of Zurich

ZORA URL: https://doi.org/10.5167/uzh-128170

Journal Article

Accepted Version

Originally published at:

Sarıdă̆, Serkan; Helvacıŏ̆lu-Yiğit, Dilek; Özcan, Mutlu; Avcu, Egemen; Kızıltaş, Güllü (2016). Micro-computerized tomography analysis of cement voids and pull-out strength of glass fiber posts luted with self-adhesive and glassionomer cements in the root canal. Journal of Adhesion Science and Technology, 30(14):1585-1595.

DOI: https://doi.org/10.1080/01694243.2016.1155911 
Micro-computerized tomography analysis of cement voids and pull-out strength of glass fiber posts luted with self-adhesive and glass-ionomer cements in the root canal

\section{Serkan Sarıdağ, DDS, PhDa / Dilek Helvacıoğlu-Yiğit, DDS, $\mathrm{PhD}^{\mathrm{b}}$ / Mutlu Özcan, DDS, Dr.med.dent., $\mathrm{PhD}^{\mathrm{C}} /$ Egemen Avcu, $\mathrm{PhD}^{\mathrm{d}} /$ Güllü Kızıltaş, $\mathrm{PhD}^{\mathrm{e}}$}

${ }^{a}$ Assistant Professor, University of Kocaeli, Faculty of Dentistry, Department of Prosthodontics, Kocaeli, Turkey

${ }^{b}$ Assistant Professor, University of Kocaeli, Faculty of Dentistry, Department of Endodontics, Kocaeli, Turkey

${ }^{c}$ Professor, University of Zurich, Dental Materials Unit, Center for Dental and Oral Medicine, Clinic for Fixed and Removable Prosthodontics and Dental Materials Science, Zurich, Switzerland

${ }^{d}$ Assistant Professor, University of Kocaeli, Faculty of Dentistry, Department of Endodontics, Kocaeli, Turkey

${ }^{e}$ Associate Professor, University of Sabanci, Faculty of Engineering, Department Natural Sciences and Mechatronics, Istanbul, Turkey

Short title: Pull out strength and cement void around fiber posts.

Correspondance to: Assist. Prof., Serkan Sarıdağ, DDS, PhD. University of Kocaeli, Faculty of Dentistry Department of Prosthodontics 41190, Kocaeli, Turkey. Tel:+90 26234422 22, Fax: +90-262-344-22-02. e-mail: ssaridag@hotmail.com 
Abstract: This study evaluated the pull-out strength of different glass fiber posts and measured volume of cement and voids in the cement in the root canal utilizing micro-computerized tomography (micro-CT) analysis after they were cemented with two different luting cements. Canine teeth $(\mathrm{N}=40)$ were endodontically treated and randomly divided into four groups depending on the fiber post and the cement type (n=10 per group) as follows: Group RU: (RelyX + RelyX U200), Group PU: (PINpost + RelyX U200), Group RF: (RelyX + FujiCEM 2), Group PF: (PINpost + FujiCEM 2). Each tooth was scanned using microCT and the percentage of cement and void volume at the coronal, middle, and apical levels was calculated. Pull-out tests were performed by applying tensile load parallel to the long axis of the posts $(0.5$ $\mathrm{mm} / \mathrm{min}$ ). Data were analyzed using, ANOVA, Kruskal-Wallis and Mann-Whitney $U$ tests (alpha=0.05). Regardless of cement type, the percentage (\%) of cement volume in the RelyX post groups (RU:31-36; $R F: 29-40)$ was significantly higher than that in the PINpost groups (PU:19-23; PF:18-22) $(p<0.05)$. The percentage of void volume at the PINpost groups (PU:6-11; PF:8-13) was significantly lower than that in the RelyX groups (RU:2; RF:3) $(p<0.05)$. No significant differences were observed in pull-out strength $(N)$ between the four experimental groups (RU:358.8 $\pm 56.2 ; R F: 299 \pm 64.8 ; P U: 311.9 \pm 61.3 ; P F: 293.1 \pm 91.3$ ) $(p>0.05)$. The micro-CT analysis demonstrated that the percentage of cement and void volumes vary depending on the type of fiber post and cement used. No correlation between cement, void volume and pull-out strength was observed.

Keywords: Fiber post, glass ionomer cement, micro-computerized tomography, micro-ct, pinpost, pull-out test, resin cements 


\section{Introduction}

Glass fiber reinforced posts are commonly used to provide adequate support and retention for the restoration of endodontically treated teeth, as their modulus of elasticity is similar to dentin. Bonding the post in the canal and core fabrication procedures requires less chair-side time than a custom-cast post and core [1]. One of the most common types of fiber post failure is the loss of retention between the post and root canal dentin [2-4]. The surface of the post in contact with the tooth increases with the increase in post diameter $[\mathrm{x}]$. According to some studies on the other hand, an increase in post diameter does not influence their retentive capacities considerably [5,6]. In addition to post length, diameter and post design, retention is also influenced by several other factors such as the luting cement, the interaction between the post-core, post-cement, and dentin-cement interfaces [7].

Resin composite cement and resin modified glass-ionomer cements (RMGICs) are the most commonly used luting cements for fiber posts [8]. Self-adhesive cements have been introduced as an alternative to conventional dual-polymerizing resin cements as they have the ideal water content [9-11]. As it requires no surface conditioning, the critical drying step after acid etching the root dentin is eliminated that makes post cementation less time consuming [12]. The significant advantage of RMGIC is its hygroscopic expansion after setting which offsets its initial setting shrinkage, thus making the dentin-cement interface more stable [13]. It has been demonstrated that adaptation of posts to root canal walls can influence the bond strength to dentin [14]. However, when the posts are not properly adapted to the root canal wall, a thicker layer of resin cement is necessary to fill any voids within the cement layer or at the post-cement and root dentincement interface. This then increases the shrinkage stress induced by polymerization of the resin cement $[15,16]$. Although many in-vitro studies have investigated the influence of cement thickness [16-22] and voids $[16,23-25]$ on the bond strength of fiber posts, there is no consensus in the literature.

Micro-computerized tomography (micro-CT), a non-destructive and reproducible imaging system, is based on reconstruction of three-dimensional (3D) images using a collection of two-dimensional (2D) projections of X-rays through a specimen. It has promising applications in different fields of dentistry $[17,26,27]$. The influence of the cement thickness on bond strength of fiber posts has been evaluated 
using longitudinal sectioning prior to photographic and microscopic analysis but this technique can also lead to loss of cement material during sectioning [x]. Another disadvantage of sectioning is that only a limited number of sections per specimen can be evaluated, and only the area of cement and voids can be analyzed $[18,19]$. Micro-CTs have recently been used to differentiate between canal walls, cement, and fiber post, and show that 3D quantitative assessment of post space volume is possible [17]. Moreover, through this technique any potential operator bias during interpretation of the results could be avoided [28]. Limited number of studies carried out a 3D volumetric evaluation of different post systems $[17,29,30]$.

The objectives of this study therefore were to evaluate the pull-out strength of different glass fiber posts and measure the volume of cement and voids in the cement in the root canal utilizing micro-CT analysis after they were cemented with two different luting cements. The following null hypotheses were tested: a) Pull-out strength of the fiber posts would not be affected by the post and the cement type, $b$ ) the amount of cement voids would not differ depending on the cement type at all levels in the root canal.

\section{Materials and Methods}

Tooth specimens

Recently extracted caries-free maxillary canine teeth $(\mathrm{N}=40)$ due to periodontal reasons with similar dimensions were selected for this study. The coronal portions were sectioned with a diamond disc under water-cooling in order to standardize the length of the specimens at $16 \mathrm{~mm}$. Calculus and soft-tissue remnants were removed using a periodontal scaler and they were cleaned using a rubber cup using fine pumice-water slurry. The presence of any pre-existing defects were examined, if present eliminated and finally the selected teeth were stored in distilled water at room temperature.

Endodontic treatment

A size $10 \mathrm{~K}$-file (Mani Inc., Tochigi-Ken, Japan) was placed passively in each root canal until it reached the apical foramen. The working length was set at $0.5 \mathrm{~mm}$ shorter than required to reach the foramen. Root canals were prepared with rotary instruments (ProTaper Universal, PTU, Dentsply Tulsa Dental Specialties, Tulsa, UK) according to the manufacturer's instructions. PTU files were operated at $300 \mathrm{rpm}$ 
with $2 \mathrm{~N} / \mathrm{cm}$ of torque using a pre-programmed device (WaveOne, Dentsply Maillefer, Ballaigues, Switzerland). All canals were prepared up to size F5 file, and irrigated with $1 \mathrm{~mL}$ of $2.5 \% \mathrm{NaOCl}$ after every change of the instrument. After canal preparation, $5 \mathrm{~mL}$ of $17 \%$ EDTA was used followed by final rinse with distilled water. The canals were then dried with paper points. The root canals were filled using the lateral condensation technique with gutta-percha and root canal filling material (AHPlus, DeTrey Dentsply, Kontanz, Germany). The teeth were then stored at $37^{\circ} \mathrm{C}$ at $100 \%$ humidity.

Post space preparation

After $24 \mathrm{~h}$, the coronal gutta-percha was removed with Gates Glidden drills \#1-3 (Mani, Tochigi, Japan), leaving a $5 \mathrm{~mm}$ apical seal. A $10 \mathrm{~mm}$ deep post space was prepared with $1.6 \mathrm{~mm}$ diameter using a matching drill (Rely-X Drill, 3M ESPE, St. Paul, MN, USA). The prepared post space was rinsed with $5 \%$ $\mathrm{NaOCl}$. Final irrigation was accomplished with distilled water, and post spaces were dried with paper points. The specimens were randomly divided into four ( $n=10$ each) groups.

Experimental groups and post placement

1. Conical fiber posts with resin cement group $(\mathrm{RU})$ : Tapered glass fiber posts $\left(1.6 \mathrm{~mm}\right.$ diameter, $4.58^{\circ}$ taper) (RelyX Fiber Post, 3M ESPE) were used in this group. The posts were cleaned with alcohol and airdried. Self-adhesive dual-polymerized resin cement (RelyX U200 Automix; 3M ESPE) was manipulated according to the manufacturer's recommendations, and then placed in the canals with an elongation tip applicator (3M ESPE) in order to allow application of the cement in the canal from apical to the coronal part. After the fiber post was seated using slight pressure, excess resin cement was removed and the remaining cement was photo-polymerized (Elipar Freelight 2, 3M ESPE) through the post for $40 \mathrm{~s}$ (Figs. 1a-b).

2. Conical fiber posts with glass ionomer cement group (RF): RMGIC (FujiCEM 2 Dispenser GC, Tokyo, Japan) was manipulated according to the manufacturer's recommendations, dispensed using an auto-mix syringe into the post space, and placed in the canals with a spiral file (Lentulo; Dentsply Maillefer Ballaigues, Switzerland) attached to a low-speed hand-piece. The RelyX fiber post was positioned in the canal with light pressure and stabilized for $3 \mathrm{~min}$. 
3. Paralel pin-post with resin cement group (PU): Two different diameters $(4 \times 0.45 \mathrm{~mm}$ and $3 \times 0.35 \mathrm{~mm})$ of parallel glass-fiber pin-posts (PINpost DentaPreg, Brno, Czech Republic) were combined in this group. Self-adhesive dual-polymerized resin cement (Rely X U200 Automix, 3M ESPE) was applied as described above, and seven fiber pin-posts were inserted according to the manufacturer's recommendations to allow maximum filling of the post space. The excess resin cement was removed and the remaining cement was photo-polymerized (Elipar Freelight 2) through the post for $40 \mathrm{~s}$.

4. Parallel pin-post with glass ionomer cement group (PF): RMGIC (FujiCEM 2 Dispenser, GC) was dispensed using an auto-mix syringe into the post space, and then placed in the canals with a lentulospiral. Parallel glass-fiber pin-posts (PINpost, DentaPreg) were positioned in the canal with light pressure and stabilized for $3 \mathrm{~min}$, similar to the RF group.

Micro-computed tomography and 3D reconstruction

High-resolution micro-CT scanner (SkyScan 1072, SkyScanb.v.b.a., Aartselaar, Belgium) was used to scan the specimens. The X-ray tube was operated at $100 \mathrm{kV}$ and $100 \mathrm{~mA}$ with $\mathrm{Al}$ and $\mathrm{Cu}$ filters, at an exposure time of $180 \mathrm{~ms}$. Long axis of the specimens were positioned perpendicular to the floor of the micro-CT specimen holder and the specimens were scanned at $360^{\circ}$ rotation with a rotation step of $0.5^{\circ}$ and image pixel size of $19.68 \mu \mathrm{m} .2 \mathrm{D}$ images were reconstructed using a software (NRecon software, SkyScan, Kontich, Belgium) and CTAN software (SkyScan, Kontich, Belgium) was used for 3D volumetric analysis (Figs. 2a-b). For each specimen, $10 \mathrm{~mm}$ of the root from the tip of the fiber post was analyzed to standardize the length of the root portion.

The analysis of the respective volumes was carried out using CTAN software. Analysis of the desired relative volumes of the specimen requires an appropriate selection of region of interest (ROI). Without ROI, the volumes could be calculated relative to the volume of the total dataset, including the air surrounding the specimen that could give an underestimation of the measured relative volume. Therefore, first the reconstructed images were opened and an appropriate ROI was selected that encompasses void from material without voids (e.g. cement, gutta-percha, post) and the volume of interest was created using interpolation. Also, the top and bottom of the ROI (in the Z-direction) were specified for each 3 region along 
the longitudinal axis of the specimen. Once an appropriate ROI (in 3D, called volume of interest) is selected, on the 'Binary images' page, a threshold was chosen to select areas that included void and certain structures (in this case, cement, gutta-percha, post) based on the grey values. Shifting between $\mathrm{xx}$ and comparing the raw image with the binary image appropriate threshold was set. In order to be able to compare different specimens, the threshold values were kept constant for all specimens. Therefore, it was verified that the selected threshold values could be applied to all specimens, which was only possible when all specimens were scanned and reconstructed with the same settings. The volumes of cement and voids were calculated using post-threshold based segmentation and quantified in $\mathrm{mm}^{3}$. Then, the percentages of volume of cement and voids were calculated using the equations below:

Volume of cement/Volume of post-space $\times 100=\%$ Volume of cement.

Volume of voids/Volume of post-space $\times 100=\%$ Volume of voids.

As for the final step, thresholds were determined and the volume of the voids or object (cement or similar) relative to the volume of interest was calculated using 3D analysis plug-in.

Pull-out test

Each tooth was embedded in an acrylic resin block along the long axis with the help of a surveyor and 2 $\mathrm{mm}$ of the root was left exposed. The pull-out test was performed parallel to the long axis of the post at a cross-head speed of $0.5 \mathrm{~mm} / \mathrm{min}$ in a Universal Testing Machine (Instron 4411, Instron Ltd., High Wycombe, United Kingdom). The force required to dislodge the fiber post was recorded in Newton $(\mathrm{N})$.

Debonded posts were also examined under stereomicroscope (Olympus SZ4045 TRPT, Osaka, Japan) at a magnification of $x 20$. Types of failure were classified in three categories: a) Adhesive: no cement left adhered on the post surface, b) Cohesive: cohesive failure of the cement on the post, c) Mixed: combination of adhesive and cohesive failures.

Statistical analysis

All statistical procedures were performed using the Statistical Package for Medical Science (SPSS Ver.11 for Windows, City, Country). The means of each group for void analysis were performed using two-way analyses of variance (2-way ANOVA) and Tukey's post hoc tests. Mean pull-out strengths were analyzed 
using Student's t-test for normally distributed data, Kruskal-Wallis test, for not normally distributed data, and Mann-Whitney U post hoc tests, for intergroup comparisons. Spearman's correlation test was used to determine the relationship between pull-out strength values and amount of cement and void volume. $\mathrm{P}$ values less than 0.05 were considered to be statistically significant in all tests.

\section{Results}

The percentage of cement volume in the RelyX post groups (RU: 31-36; RF: 29-40) was significantly higher than that in the PINpost groups (PU: 19-23; PF: 18-22) at apical, middle and coronal levels $(p<0.05)$ (Table 1a).

Regardless of the level in the root, the percentage (\%) of void volume at the PINpost groups (PU: 6-11; PF: 8-13) was significantly lower than that in the RelyX groups (RU: 2; RF:3) $(p<0.05)$ (Table 1b).

No significant differences were observed in pull-out strength $(\mathrm{N})$ between the four experimental groups

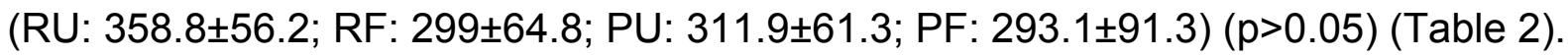

\section{Pull-out strength values did not correlate with the cement volume and the void volume in the cement.}

While RU group presented predominantly cohesive failure type, PU group showed similar incidence of adhesive and mixed type failures (Table 3). Adhesive failures were more common in the RF group but RU group exhibited similar numbers of adhesive and mixed failure types.

Representative stereo-microscopic images from adhesive, cohesive, and mixed type failures are presented in Figs. 3a-c.

\section{Discussion}

This study aimed to evaluate the pull-out strength of different glass-fiber posts cemented with either selfadhesive or resin modified glass ionomer cement and measure the volume of cement and voids in the cement in the root canal. Based on the results of this study, since pull-out strength results did not show significant difference between different glass fiber post systems and cement combinations, the first hypothesis could be accepted. On the other hand, the cement and void volume showed variations 
depending on the post type and the cement type, yet being not significant at the apical, middle or coronal levels in the root. Thus, the second hypothesis could be partially rejected.

The production of anatomic posts and use of accessory posts has been recommended as they require thin cement layer, promote retention, and prevent adhesive defects by increasing the quantity of fibers [31]. In previous studies, the increase in the diameter of the post did not result in a significant increase in retention $[6,32]$ which could be also confirmed in this study. To the best of our knowledge, there are no studies that investigated the pull-out strength of narrow diameter parallel glass fiber pin-post with which without using a one piece main post, an anatomical post could be achieved with multiple single fibers.

Analysis of the failure modes of self-adhesive resin cement groups showed that most of the failures occurred cohesively in the cement followed by mixed failures, while the incidence of adhesive failures were more common with the posts cemented with RMGIC. This may be attributed to the lower cohesive strength of RMGIC materials despite the fact that they chemically bond to apatite containing tooth substrates [33].

In this study, the root canal diameter was standardized before post cementation. Although no significant differences were observed in the pull-out strengths between the groups, RelyX posts showed a significantly higher total volume of cement than pin-posts. Ideally, an interface between the post and dentin should be free of gaps to produce a homogeneous monoblock structure, a situation which was initially expected [34]. The technique of cementing the glass-fiber pinposts of $0.45 \mathrm{~mm}$ diameter with additional pin-posts with $0.35 \mathrm{~mm}$ diameter might have led to a reduction in the amount of cement present in the root canal, which is in fact similar to lateral obturation technique. Although increased fiber amount yielded to less cement volume and thin cement film compared to one piece posts, they led to an increase in the amount of voids in the root canal. One reason for this could be incorporation of more air bubbles, each time a thin post is placed on the root canal. On the contrary, with one-piece posts, the likelihood of introducing voids is only once when they are luted in the root canal.

Assessment using micro-CT, instead of conventional techniques such as SEM or optical microscopy, may result in lower accuracy. In one study, micro-CT was employed to examine the volume of cement and voids in endodontically treated teeth restored with different fiber posts and the volume of luting cement 
around oval and circular fiber posts [17]. In that study, the oval posts showed significantly higher surrounding cement thickness than the circular post group. However, no bond strength or pull-out strength tests were conducted [17]. The present study demonstrated that the volume of resin cement did not influence the pull-out strength in any of the groups. In contrast, D'Arcangelo et al. [35] evaluated the effect of 4 different post-space diameters and related resin cement film thicknesses to the bond strength between fiber posts and root dentin where improved bond strength results were observed when thinner posts were used. Similarly, in another study, resin cement thickness was analyzed using photographs of the fiber post under optical microscope [18]. They reported that an increase in cement thickness did not significantly affect the push-out bond strength. Other studies $[36,37]$ and this study indicated that increased cement thickness did not increase the pull-out strength.

Limited number of studies investigated the presence, distribution, and influence of voids in the literature. Rengo et al analyzed micro-CT images of voids in the root canals and found that regardless of the post shape, the volume of voids and resin cement was significantly higher at the coronal level [17]. In that study, the injection technique with specific syringes was used for the application of the resin cements, and this appears to be preferred as an effective method for reducing voids and bubbles within the luting cement [38]. Thus, in this study, self-adhesive resin cements was applied with the elongation tip which showed significantly less void volume than RMGIC cemented groups applied directly with a lentulo-spiral, regardless of the fiber post type used. Future studies should focus on microbiological aspects in the postcement combinations presenting different amounts of voids.

\section{Conclusions}

From this study, the following could be concluded:

1. Both glass-fiber posts, composed of either one piece (RelyX fiber post) or multiple fibers (PINpost) presented similar pull-out strength with both self-adhesive or resin modified glass ionomer cement tested.

2. The cement volume in the root canal was significantly less in the PINpost than those in the RelyX glass fiber post groups but percentage of void volumes was the opposite. 
3. Pull-out strength values did not correlate with the cement volume and the void volume in the

\section{cement.}

4. Cohesive failures in the cement were more common when both post materials were cemented with self-adhesive resin cement (RelyX U200) compared to resin modified glass-ionomer (FujiCEM 2) where mainly adhesive or mixed failures were noted.

\section{Clinical Relevance}

Pinpost and RelyX fiber posts cemented either with self-adhesive resin or resin modified glass-ionomer cements showed similar pull-out strength.

\section{Conflict of interest}

The authors did not have any commercial interest in any of the materials used in this study.

\section{Acknowledgements}

The authors would like to acknowledge 


\section{References}

1. Asmussen E, Peutzfeldt A, Heitmann T. Stiffness, elastic limit, and strength of newer types of endodontic posts. J Dent 1999;27:275-278.

2. Naumann M, Koelpin M, Beuer F, Meyer-Lueckel H. Ten-year survival evaluation for glass-fibersupported postendodontic restoration: a prospective observational clinical study. J Endod 2012;38:432435.

3. Monticelli F, Grandini S, Goracci C, Ferrari M. Clinical behaviour of translucent-fiber posts: a 2-year prospective study. Int J Prosthodont 2003;16:593-596.

4. Akgungor G, Akkayan B. Influence of dentin bonding agents and polymerization modes on the bond strength between translucent fiber posts and three dentin regions within a post space. J Prosthet Dent 2006;95:368-378.

5. Nergiz I, Schmage P, Özcan M, Platzer U. Effect of length and diameter of tapered posts on the retention. J Oral Rehabil 2002;29:28-34.

6. Stockton LW. Factors affecting retention of post systems: a literature review. J Prosthet Dent 1999;81:380-385.

7. Ferrari M, Vichi A, Garcia-Godoy F. Clinical evaluation of fiber-reinforced epoxy resin posts and cast post and cores. Am J Dent 2000;13:15-18.

8. Jokstad A, Mjör IA. Ten years' clinical evaluation of three luting cements. J Dent 1996;24:309-315.

9. Bergoli CD, Amaral M, Boaro LC, Braga RR, Valandro LF. Fiber post cementation strategies: effect of mechanical cycling on push-out bond strength and cement polymerization stress. J Adhes Dent 2012;14:471-478.

10. Radovic I, Monticelli F, Goracci C, Vulicevic ZR, Ferrari M. Self-adhesive resin cements: a literature review. J Adhes Dent 2008;10:251-258.

11. Shiratori FK, Valle AL, Pegoraro TA, Carvalho RM, Pereira JR. Influence of technique and manipulation of self-adhesive resin cements used to cement intraradicular posts. J Prosthet Dent 2013;110:56-60. 
12. Bouillaguet S, Troesch S, Wataha JC, Krejci I, Meyer JM, Pashley DH. Microtensile bond strength between adhesive cements and root canal dentin. Dent Mater 2003;19:199-205.

13. Pereira JR, Vidotti HA, Valle AL, Pamato S, Ghizoni JS, Lorenzoni FC. SEM analysis and push-out bond strength of fiberglass posts luted with different cements of glass-ionomer in humid environment: pilot test. J Res Dent 2013;1:83-90.

14. Lloyd PM, Palik JF. The philosophies of dowel diameter preparation: a literature review. J Prosthet Dent 1993;69:32-36.

15. Giachetti L, Scaminaci Russo D, Bertini F, Giuliani V. Translucent fiber post cementation using a lightcuring adhesive/composite system: SEM analysis and pull-out test. J Dent 2004;32:629-634.

16. Latempa AM, Almeida SA, Nunes NF, da Silva EM, Guimarães JG, Poskus LT. Techniques for restoring enlarged canals: an evaluation of fracture resistance and bond strength. Int Endod J 2015;48:2836.

17. Rengo C, Spagnuolo G, Ametrano G, Ferrari M. Micro-computerized tomographic analysis of premolars restored with oval and circular posts. Clin Oral Investig 2014;18:571-578.

18. Perez BE, Barbosa SH, Melo RM, Zamboni SC, Özcan M, Valandro LF, Bottino MA. Does the thickness of the resin cement affect the bond strength of a fiber post to the root dentin? Int J Prosthodont 2006;19:606-609.

19. da Rosa RA, Bergoli CD, Kaizer OB, Valandro LF. Influence of cement thickness and mechanical cycling on the push-out bond strength between posts and root dentin. Gen Dent 2011;59:156-161.

20. Egilmez F, Ergun G, Cekic-Nagas I, Vallittu PK, Lassila LV. Influence of cement thickness on the bond strength of tooth colored posts to root dentin after thermal cycling. Acta Odontol Scand 2013; 71:175-182. 21. Er O, Kılıç K, Kılınç HI, Aslan T, Sağsen B. Evaluation of the resin cement thicknesses and push-out bond strengths of circular and oval fiber posts in oval-shapes canals. J Adv Prosthodont 2015;7:15-20.

22. Sahafi A, Benetti AR, Flury S, Peutzfeldt A. Retention of root canal posts: Effect of cement film thickness, luting cement, and post pretreatment. Oper Dent 2015 (EPub). 
23. Uzunoğlu E, Türker SA, Yilmaz Z. Influence of cement type and thickness on polyfiber post adhesion. JCD 2014;17:255-260.

24. Grandini S, Goracci C, Monticelli F, Borracchini A, Ferrari M. SEM evaluation of the cement layer thickness after luting two different posts. J Adhes Dent 2005;7:235-240.

25. Mannocci F, Innocenti M, Ferrari M, Watson TF. Confocal and scanning electron microscopic study of teeth restored with fiber posts, metal posts, and composite resins. J Endod 1999;25:789-794.

26. Vichi A, Grandini S, Davidson CL, Ferrari M. An SEM evaluation of several adhesive systems used for bonding fiber posts under clinical conditions. Dent Mater 2002;18:495-502.

27. Carrera CA, Lan C, Escobar-Sanabria D, Li Y, Rudney J, Aparicio C, Fok A. The use of micro-CT with image segmentation to quantify leakage in dental restorations. Dent Mater 2015;31:382-90.

28. Solomonov M, Paqué F, Kaya S, Adigüzel O, Kfir A, Yiğit-Özer S. Self-adjusting files in retreatment: a high-resoluton micro-computed tomography study. J Endod 2012;38:1283-1287.

29. Neves AA, Jaecques S, Ende AV, Cardoso MC, Coutinho E, Lührs AK, Zicari F, Meerbeek BV. 3Dmicroleakage assessment of adhesive interfaces: Exploratory findings by $\mu C T$. Dent Mater 2014;30:799807.

30. Lazari PC, Oliveira RC, Anchieta RB, Almeida EO, Freitas Junior AC, Kina S, Rocha EP. Stress distribution on dentin-cement-post interface varying root canal and glass fiber post diameters. A threedimensional finite element analysis based on micro-CT data. J Appl Oral Sci 2013;21:511-517.

31. Martelli Junior H, Pellizzer EP, Rosa BT, Lopes MB, Gonini Junior A. Fracture resistance of structurally compromised root filled bovine teeth restored with accessory glass fiber posts. Int Endod J 2008;41:685692.

32. Amanajas Neto GP, Pinto WRS, Klautau EB, Alves BP. Pull-out strength of endodontically treated teeth restored with glass fiber posts of different diameters. Rev Gaúcha Odontol 2011;59:609-614.

33. Li XJ, Zhao SJ, Niu LN, Tay FR, Jiao K, Gao Y, Chen JH. Effect of luting cement and thermomechanical loading on retention of glass fiber posts in root canals. J Dent 2014;42:75-83. 
34. Tay FR, Pashley DH. Monoblocks in root canals: a hypothetical or a tangible goal. J Endod 2007;33:391-398.

35. D'Arcangelo C, Cinelli M, De Angelis F, D'Amario M. The effect of resin cement film thickness on the pullout strength of a fiber-reinforced post system. J Prosthet Dent 2007;98:193-198.

36. Huber L, Cattani-Lorente M, Shaw L, Krejci I, Bouillaguet S. Push-out bond strengths of endodontic posts bonded with different resin-based luting cements. Am J Dent 2007;20:167-172.

37. Perdigao J, Gomes G, Augusto V. The effect of dowel space on the bond strengths of fiber posts. J Prosthodont 2007;16:154-164.

38. Kim SR, Yum J, Park JK, Hur B, Kim HC. Comparison of push-out bond strength of post according to cement application methods. J Korean Acad Conserv Dent 2010;35:479-485. 


\section{Captions to tables and figures:}

\section{Tables:}

Table 1a. Mean and standard deviation (SD) of the a) cement b) void volume measured in each experimental group. Different lowercase superscript letters in each column indicate significant difference $(p<0.05)$. RU: RelyX + RelyX U200; PU: PINpost + RelyX U200; RF: RelyX + FujiCEM 2; PF: PINpost + FujiCEM 2.

Table 2. Mean and standard deviation (SD) of pull-out strength (N) in each experimental group. Same lowercase superscript letters in each column indicate no significant difference $(p>0.05)$.

Table 3. Distribution of failure types in each experimental group.

\section{Figures:}

Figs. 1a-b. Cross section of a root canal that received a) PINpost and b) RelyX post.

Figs. 2a-b. Representative 3D images of root canals that received a) PINpost and b) RelyX post. Posts are shown in white, gutta-percha in orange, and cement in blue.

Figs. 3a-c. Representative photos of three failure types a) Adhesive: no cement left adhered on the post surface, b) Cohesive: cohesive failure of the cement on the post, c) Mixed: combination of adhesive and cohesive failures. 


\section{Tables:}

\begin{tabular}{|c|c|c|c|}
\hline Experimental Groups & $\begin{array}{c}\text { Apical (\%) } \\
\text { (mean } \pm S D)\end{array}$ & $\begin{array}{l}\text { Middle (\%) } \\
\text { (mean } \pm S D)\end{array}$ & $\begin{array}{c}\text { Coronal (\%) } \\
\text { (mean士SD) }\end{array}$ \\
\hline RU & $31.3 \pm 9.4^{\mathrm{a}}$ & $36 \pm 10.4^{a}$ & $36.4 \pm 5.4^{\mathrm{a}}$ \\
\hline PU & $18.7 \pm 8.7^{b}$ & $20.8 \pm 9.2^{b}$ & $22.6 \pm 9.1^{b}$ \\
\hline RF & $28.8 \pm 8.1^{a}$ & $33.9 \pm 6.5^{\mathrm{a}}$ & $39.5 \pm 5.7^{\mathrm{a}}$ \\
\hline PF & $18.2 \pm 4.9^{b}$ & $19.1 \pm 4^{\mathrm{b}}$ & $21.9 \pm 5.8^{b}$ \\
\hline
\end{tabular}

Table 1a. Mean and standard deviation (SD) of the cement volumes measured in each experimental group. Different lowercase superscript letters in each column indicate significant difference $(p<0.05)$. RU: RelyX + RelyX U200; PU: PINpost + RelyX U200; RF: RelyX + FujiCEM 2; PF: PINpost + FujiCEM 2.

\begin{tabular}{|c|c|c|c|}
\hline Experimental Groups & $\begin{array}{c}\text { Apical (\%) } \\
\text { (mean士SD) }\end{array}$ & $\begin{array}{l}\text { Middle (\%) } \\
\text { (mean } \pm S D)\end{array}$ & $\begin{array}{l}\text { Coronal (\%) } \\
\text { (mean } \pm \text { SD) }\end{array}$ \\
\hline RU & $1.8 \pm 1.7^{\mathrm{a}}$ & $2.1 \pm 2.4^{\mathrm{a}}$ & $1.6 \pm 1.6^{\mathrm{a}}$ \\
\hline PU & $6.1 \pm 4.1^{b}$ & $10.7 \pm 4.6^{b}$ & $11 \pm 4.2^{b}$ \\
\hline RF & $3.3 \pm 3.4^{\mathrm{a}}$ & $2.7 \pm 2.5^{\mathrm{a}}$ & $2.5 \pm 1.9^{a}$ \\
\hline PF & $7.7 \pm 2.7^{\mathbf{b}}$ & $12.6 \pm 3.4^{b}$ & $12.1 \pm 3^{b}$ \\
\hline
\end{tabular}

Table 1b. Mean and standard deviation (SD) of the void volume measured in each experimental group. Different lowercase superscript letters in each column indicate significant difference $(p<0.05)$. 


\begin{tabular}{|l|c|}
\hline Experimental Groups & Mean \pm SD (N) \\
\hline RU & $358.8 \pm 56.2^{\mathrm{a}}$ \\
PU & $299 \pm 64.8^{\mathrm{a}}$ \\
RF & $311.9 \pm 61.3^{\mathrm{a}}$ \\
PF & $293.1 \pm 91.3^{\mathrm{a}}$ \\
\hline
\end{tabular}

Table 2. Mean and standard deviation (SD) of pull-out strength $(N)$ in each experimental group. Same lowercase superscript letters in each column indicate no significant difference $(p>0.05)$.

\begin{tabular}{|l|ccc|}
\hline Experimental Groups & Adhesive & Cohesive & Mixed \\
\hline RU & 1 & 5 & 4 \\
PU & 2 & 4 & 4 \\
RF & 5 & 1 & 4 \\
PF & 5 & - & 5 \\
\hline
\end{tabular}

Table 3. Distribution of failure types in each experimental group. 


\section{Figures:}

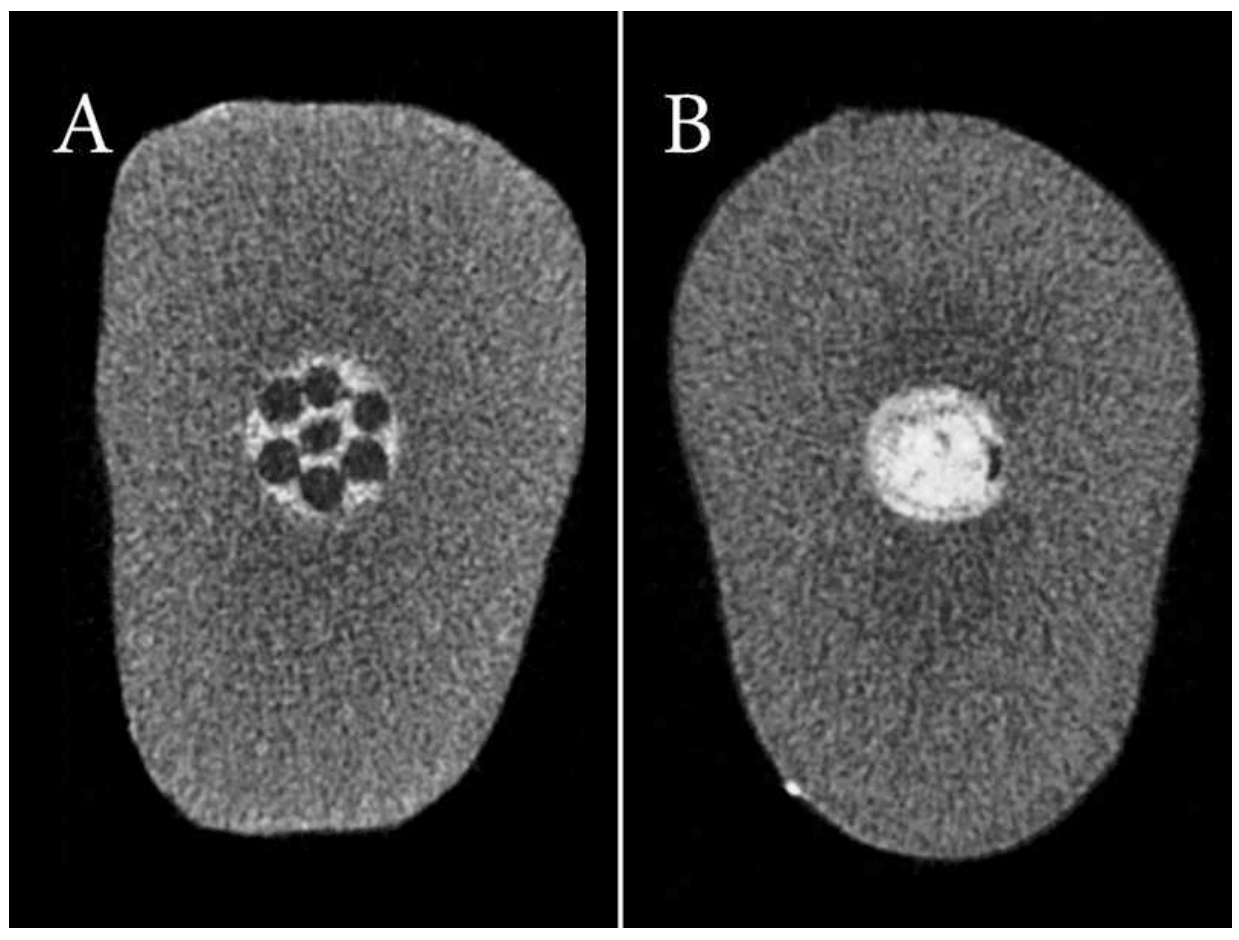

Figs. 1a-b. Cross section of a root canal that received a) PINpost and b) RelyX post. 


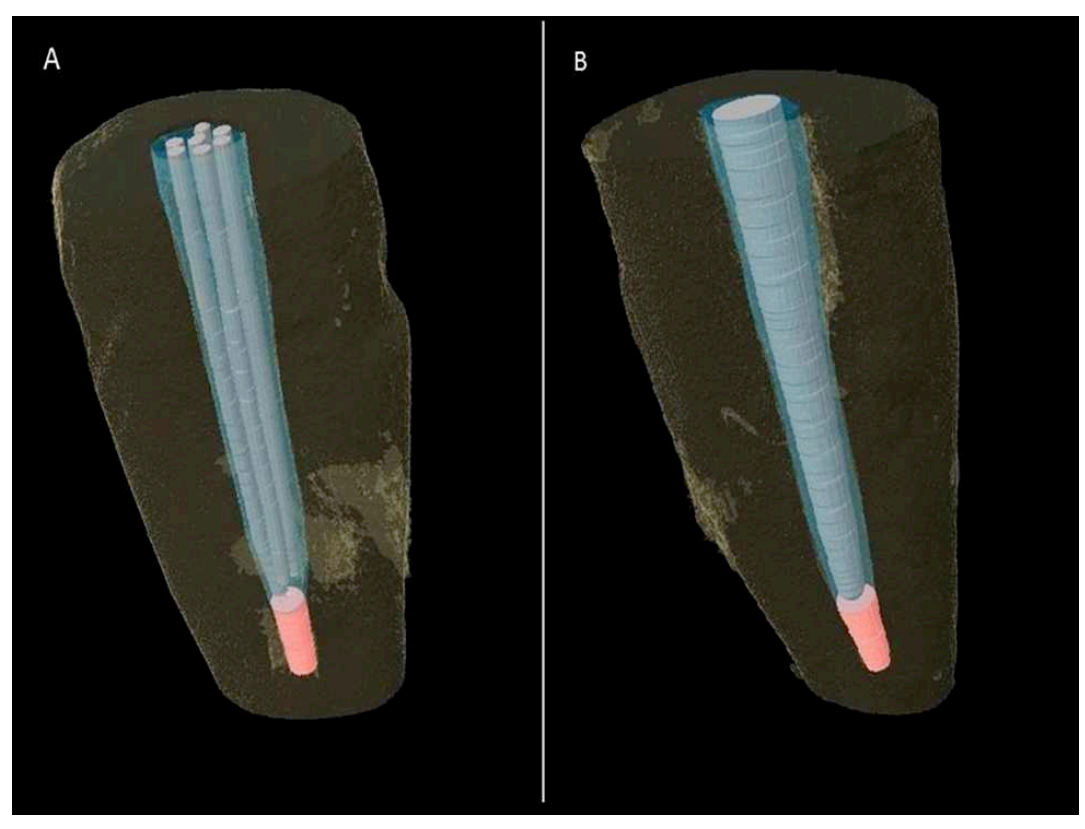

Figs. 2a-b. Representative 3D images of root canals that received a) PINpost and b) RelyX post. Posts are shown in white, gutta-percha in orange, and cement in blue.

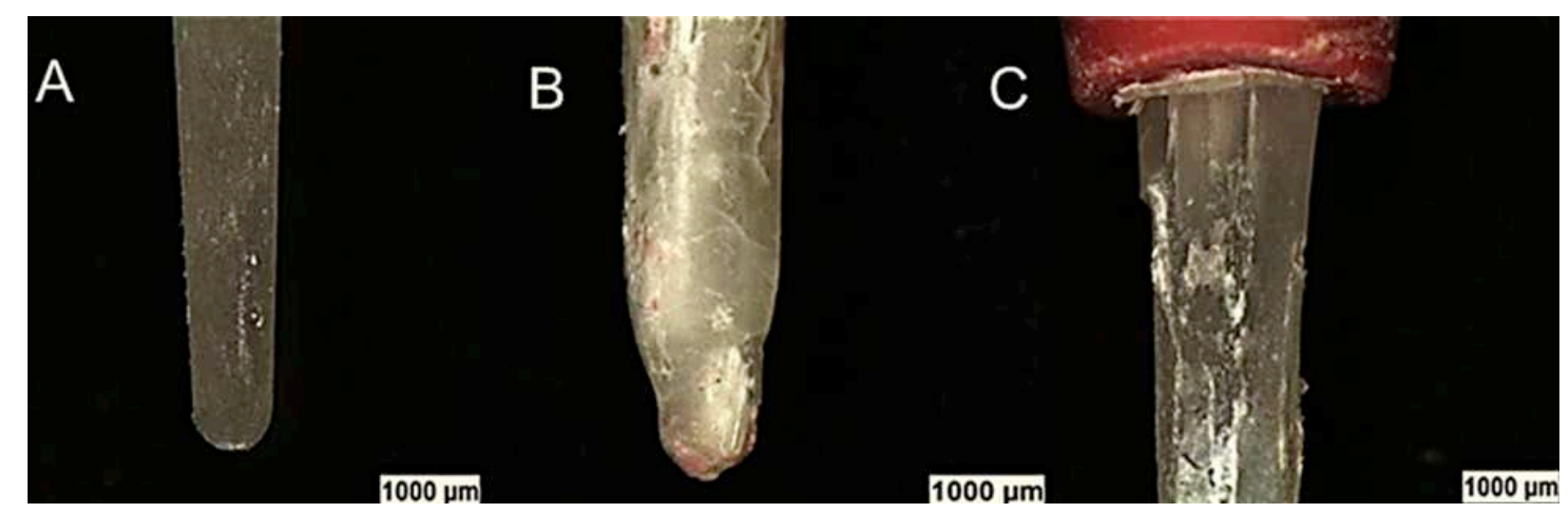

Figs. 3a-c. Representative photos of three failure types a) Adhesive: no cement left adhered on the post surface, b) Cohesive: cohesive failure of the cement on the post, c) Mixed: combination of adhesive and cohesive failures. 